treatment with the DPP-IV inhibitor FE 9990111 delays the development of diabetes, indicating a potential use for this drug class in combating the progression from impaired glucose tolerance to type 2 diabetes.

One issue to be addressed in the future clinical development of DPP-IV inhibition is that DPP-IV has several other endogenous substrates, including neuropeptides such as substance $P$, which might accumulate adversely. However, in terms of potential side effects, DPP-IV inhibitors have a key advantage over other treatment approaches: because their ability to promote insulin release is strongly glucose dependent, the risk of hypoglycaemia - the most serious side effect of current therapies - is limited.

(B) References and links Peter Kirkpatrick ORIGINAL RESEARCH PAPERS Ahrén, B. et al. Inhibition of dipeptidyl peptidase IV improves metabolic control over a 4-week study period in type 2 diabetes. Diabetes Care 25, 869-875 (2002) | Pospisilik, J. A. et al. Long-term treatment with dipeptidyl peptidase IV inhibitor P32/98 causes sustained improvements in glucose tolerance, insulin sensitivity, hyperinsulinemia and $\beta$-cell glucose responsiveness in VDF (fa/fa) Zucker rats. Diabetes 51, 943-990 (2002) | Sudre, B. et al. Chronic inhibition of circulating dipeptidyl peptidase IV by FE 999011 delays the occurrence of diabetes in male Zucker diabetic fatty rats. Diabetes 51, 1461-1469 (2002)

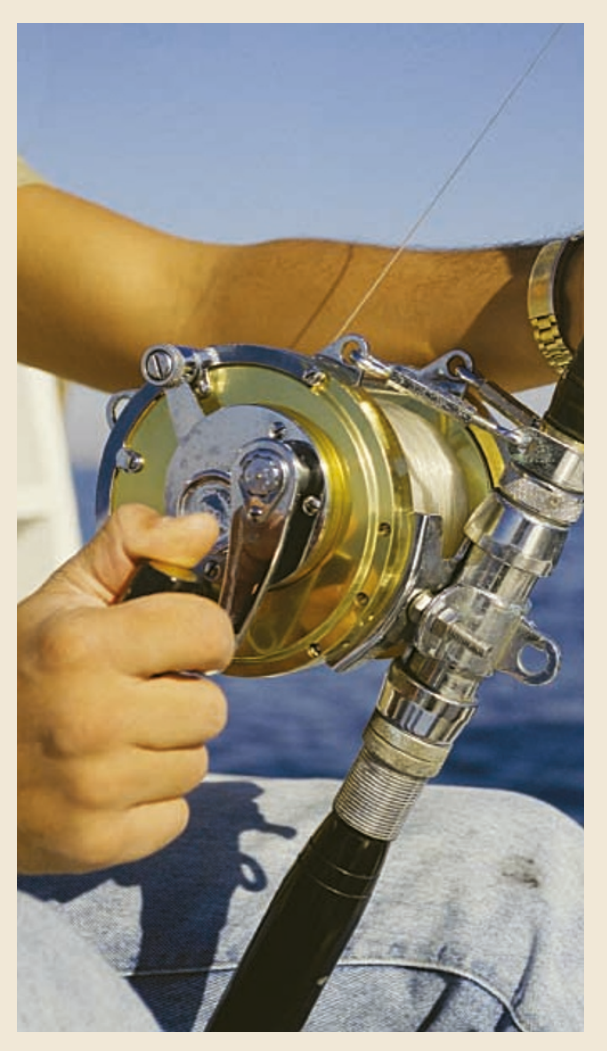

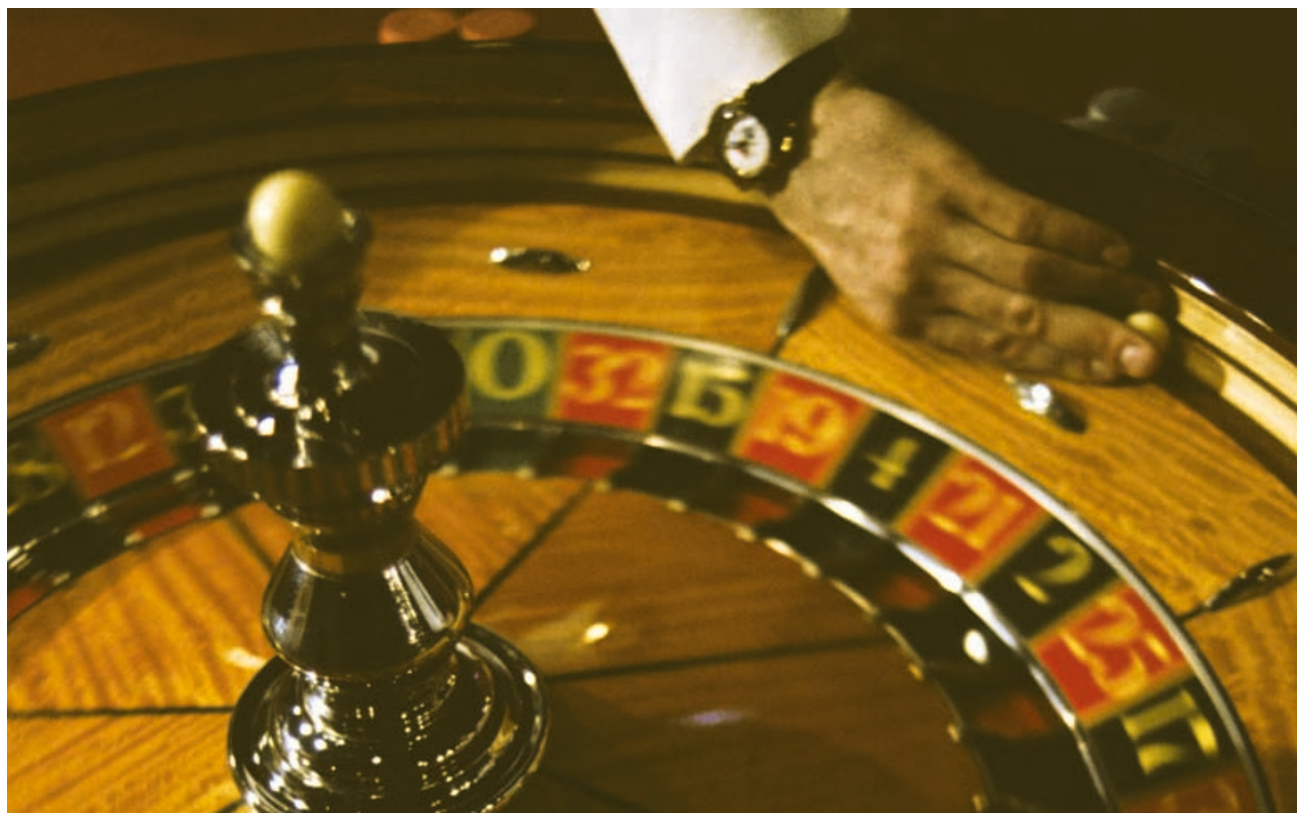

IMMUNE REGULATION

\title{
Place your T-BET on Crohn's disease
}

The transcription factor T-BET is a master switch for T-cell-mediated chronic intestinal inflammation in inflammatory bowel disease (IBD) and the regulation of protective immune responses by the cytokine transforming growth factor- $\beta$ (TGF- $\beta$ ), according to new research in the Journal of Experimental Medicine. The balance between pro- and anti-inflammatory cytokines secreted by $T$ cells regulates the initiation and continuation of IBD. The two main forms of autoimmune IBD in humans are Crohn's disease, which can affect any part of the gastrointestinal tract, and ulcerative colitis, which is restricted to the large bowel.

Generally, $\mathrm{T}$ cells fall into two categories: T-helper type $1\left(\mathrm{~T}_{\mathrm{H}} 1\right)$ cells regulate inflammation, and $\mathrm{T}_{\mathrm{H}} 2$ cells assist in the production of antibodies. Whereas Crohn's disease is associated with increased production of the $\mathrm{T}_{\mathrm{H}}$ 1-type cytokines interferon- $\gamma($ IFN- $\gamma$ ) and tumour necrosis factor, ulcerative colitis is associated with the production of large amounts of the $\mathrm{T}_{\mathrm{H}} 2$ cytokine interleukin (IL)-5. TGF- $\beta$, which is secreted by other immune cells as well as a population of regulatory $\mathrm{T}$ cells, seems to counteract the effects of these inflammatory $T_{H} 1$ and $\mathrm{T}_{\mathrm{H}} 2$ cytokines in IBD animal models. T-BET, a member of the T-box transcription-factor family, is expressed by IFN- $\gamma$-producing $\mathrm{T}_{\mathrm{H}} 1$ cells but not by $\mathrm{T}_{\mathrm{H}} 2$ cells. Furthermore, transduced expression of T-BET in developing $\mathrm{T}$ cells, or even mature $T_{H} 2$ cells, induces high levels of $T_{H} 1$ cytokine IFN- $\gamma$ production and repressed production of $\mathrm{T}_{\mathrm{H}} 2$ cytokines, including IL- 4 and IL-5. This evidence that T-BET is a master switch for both $\mathrm{T}_{\mathrm{H}} 1$-cell development and effector function indicated that it might have a key role, and be a useful therapeutic target, in IBD.

To test this hypothesis, the authors isolated lamina propria $\mathrm{T}$ cells from patients suffering from IBD. T-BET is expressed in the nuclei of T cells from patients with Crohn's disease, but not in those with ulcerative colitis or control subjects. In models of IBD, mice lacking T-bet revealed that T-bet-deficient $\mathrm{T}$ cells fail to induce $\mathrm{T}_{\mathrm{H}} 1$ mediated disease, whereas IL-4-mediated disease is exacerbated. Conversely, overexpression of T-bet resulted in an earlier, more severe, $\mathrm{T}_{\mathrm{H}} 1$ mediated disease. Transferring regulatory $\mathrm{T}$ cells from T-bet-deficient mice has an enhanced protective capacity that is probably caused by increased TGF- $\beta$ production.

T-bet seems to be a master regulator of $\mathrm{T}_{\mathrm{H}} 1$ cells, and as such, is a useful therapeutic target for diseases mediated by $\mathrm{T}_{\mathrm{H}} 1$ cells, such as Crohn's disease. However, in the T-bet-deficient mouse, the profound deficiencies in IFN- $\gamma$ lead to an imbalance in T-cell activity, rendering the mice susceptible to infectious attack and spontaneous asthma - a sign of too much $\mathrm{T}_{\mathrm{H}} 2$ activity. In addition to blocking T-bet to prevent $\mathrm{T}_{\mathrm{H}} 1$-mediated diseases, an increase in T-bet expression might be a useful therapeutic approach to $\mathrm{T}_{\mathrm{H}} 2$-mediated diseases.

(D) References and links Melanie Brazil

ORIGINAL RESEARCH PAPER Neurath, M. F. The transcription factor T-bet regulates mucosal T cell activation in experimental colitis and Crohn's disease. J. Exp. Med. 195, 1129-1143 (2002) WEB SITES

Glimcher's laboratory:

http://www.hms.harvard.edu/dms/immunology/fac_glimcher.html Blumberg's laboratory:

http://www.hms.harvard.edu/dms/immunology/fac_blumberg.html Encyclopedia of Life Sciences: http://www.els.net Encyclopedia of Life Sciences: htt
Crohn disease and ulcerative colitis 